\title{
Polytobacco use among a nationally- representative sample of black high school students
}

Tamika D. Gilreath ${ }^{*^{*}}$ D, Derek T. Dangerfield $\|^{2}$, Francisco A. Montiel Ishino ${ }^{3}$, Ashley V. Hill ${ }^{4}$ and Renee M. Johnson ${ }^{5}$

\begin{abstract}
Background: Studies of the patterns of polytobacco use have increased. However, understanding the patterns of using multiple tobacco products among Black adolescents is minimal. This study identified the patterns of polytobacco use among U.S. Black adolescents.

Methods: Latent class analysis (LCA) was used to identify patterns of adolescent polytobacco use among a representative sample of Black youth from the 2017 Youth Risk Behavior Survey $(n=2782)$. Ever and recent (past 30 day) use of cigarettes, electronic cigarettes, cigars, and dip or chewing tobacco were used as latent class indicators. Multinomial regression was conducted to identify the association if smoking adjusting for sex, age, grade, and marijuana use.

Results: Most students were in the 9th grade (29\%), e-cigarette users (21\%) and were current marijuana users (25\%). Three profiles of tobacco use were identified: Class 1: Non-smokers (81\%), Class 2: E-cigarette Users (14\%), and Class 3: Polytobacco Users (5\%). Black adolescent Polytobacco users were the smallest class, but had the highest conditional probabilities of recent cigarette use, e-cigarette use, ever smoking cigars or chewing tobacco. Ever and current use of marijuana were associated with increased odds of being in the e-cigarette user versus non-smoker group, and current marijuana use was associated with increased odds of polytobacco use (aOR $=24.61, \mathrm{Cl}=6.95-87.11)$.
\end{abstract}

Conclusions: Findings suggests the need for targeted interventions for reducing tobacco use and examining the unique effects of polytobacco use on Black adolescents. Findings confirm a significant association of marijuana use with tobacco use.

\section{Background}

Tobacco use is the single largest contributor to preventable deaths in the United States and is responsible for a considerable portion of excess morbidity and mortality among Black Americans [1-6]. Racial/ethnic differences in smoking-related health problems stem from a variety of factors, including smoking prevalence, types of products smoked (e.g., menthol cigarettes), differences in the nicotine metabolism rate, and social adversity that makes quitting more difficult for some racial/ethnic groups such as Black Americans [7-10]. The addictive characteristics and health effects of tobacco use are more difficult to treat with longer and greater exposure [11], thus Blacks who used tobacco in adolescence are at higher risk for increased adverse health outcomes across their life-course that contribute to health disparities in the United States.

\footnotetext{
* Correspondence: tgilreath@tamu.edu

'Department of Health \& Kinesiology, College Station, Texas A \& M University, 267 Gilchrist, 4243 TAMU, College station, TX 77843-4243, USA

Full list of author information is available at the end of the article
}

C C The Author(s). 2021 Open Access This article is licensed under a Creative Commons Attribution 4.0 International License, which permits use, sharing, adaptation, distribution and reproduction in any medium or format, as long as you give appropriate credit to the original author(s) and the source, provide a link to the Creative Commons licence, and indicate if changes were made. The images or other third party material in this article are included in the article's Creative Commons licence, unless indicated otherwise in a credit line to the material. If material is not included in the article's Creative Commons licence and your intended use is not permitted by statutory regulation or exceeds the permitted use, you will need to obtain permission directly from the copyright holder. To view a copy of this licence, visit http://creativecommons.org/licenses/by/4.0/ The Creative Commons Public Domain Dedication waiver (http://creativecommons.org/publicdomain/zero/1.0/) applies to the data made available in this article, unless otherwise stated in a credit line to the data. 


\section{Tobacco use among U.S. high school students}

Recent (past 30-day) use of any tobacco product among U.S. high school students declined from $24.2 \%$ to 19.6.\% between 2011 to 2017 [12]. However, data from 2019 indicate that this has increased to 23\% [13] Black youth had the lowest prevalence of any current tobacco product use (25.4\%) compared to White (35.6\%) and Latinx (26.6\%) high school students in 2019 [13]. Driving the increase in recent tobacco product use is The use of electronic cigarettes. E-cigarette use among this population has increased drastically since their introduction in 2007 [14] and it has been estimated that $27.5 \%$ of high school students report recent use of e-cigarettes [13]. Further, $10.8 \%$ of high school students concurrently use more than two tobacco products [13]. Black youth have the second highest prevalence of polytobacco use (11.5\%) compared to White youth (12\%) and Latinx youth (8.5\%) [13]. Given the evolving mix of tobacco/ nicotine products available to youth, research that investigates polytobacco use is needed. Because adolescence is a crucial period for tobacco use initiation, characterizing the unique patterns of tobacco use among Black youth is an important step to developing prevention programs for the modern tobacco era.

\section{Co-use of marijuana and tobacco and black youth}

Epidemiological studies have consistently found an association between tobacco and marijuana use in youth and young adults $[15,16]$; however, Black youth are more likely to report co-use $[15,17,18]$. Co-use of tobacco and marijuana is of particular interest given the documented disparities in tobacco-related health outcomes $[1,11]$ as well as in health and social outcomes of marijuana use [19] experienced by U.S. Blacks. Further, in the context of the changing landscape of both tobacco and marijuana legislation, examining the likelihood of polytobacco use (use of more than two tobacco products) is important.

Given the evolving landscape, more detailed examination of the patterns of polytobacco use is important in order to assess the health effects associated with different combinations of use [20-22]. Despite the importance of reducing tobacco health disparities, the literature examining current polytobacco use exclusively among Black adolescents is limited [23, 24]. As a burgeoning area, it has become clear that some youth and adults are using multiple products concurrently. In addition to long-term health issues, it is also important to recognize that tobacco use may be a marker of risk for proximal behavioral health problems in adolescence, such as poor academic achievement, depressive symptoms, and lack of social integration among adolescent Blacks [11]. Additionally, Black adolescents who initiate smoking are more likely to leave home at a younger age and have less familial interaction transitioning into adulthood [25].

\section{The current study}

Although studies on the patterns of polytobacco use have increased, most of these studies used cumbersome combination models that limited the ability to characterize patterns of co-occurring use [26-28]. Our purpose is to determine the patterns of polytobacco use among U.S. Black adolescents. Latent class analysis (LCA) is useful in identifying homogeneous subgroups within a heterogeneous population regarding the manifestations of a set of characteristics, such as the likelihood of using multiple tobacco products [29]. Given the known associations of tobacco and marijuana use particularly among U.S. Black youth, we examined marijuana use as it relates to profiles of tobacco use behaviors. We also examined differences in profiles of tobacco use by sex and grade level because use has been historically higher among boys and older adolescents. This study fills an important gap in the literature about patterns of tobacco use among Black youth for the e-cigarette era. Because Blacks experience disproportionate health problems from their tobacco use, our findings will provide epidemiological data that can be used to inform policy development and prevention programs.

\section{Methods}

Data from this study come from the 2017 U.S. Centers for Disease Control and Prevention (CDC) Youth Risk Behavior Surveillance System (YRBS), a biennial survey to monitor health behaviors including substance use, violence, sexual risk behaviors, and mental health among 9th-12th graders. The survey utilizes a three-stage cluster sampling design to yield representative estimates of the prevalence of risk behaviors among high school students [30]. Our study used the 2017 survey and included students who self-identified as non-Hispanic Black (i.e., multi-racial youth were not included), and excluded respondents missing data on key variables $(n=2782)$ from the total sample of 14,765 . The analysis of this publically available non-identifiable data was not subject to review by institutional review board pursuant to United States Code of Federal Regulations $\$ 46.101$ and $\$ 46.104$.

\section{Latent class indicators}

The 2017 YRBS included 95 items covering a range of domains including substance use, mental health and other health-related behaviors. Tobacco use was measured by the following items:

\section{Cigarette use}

Participants were asked "Have you ever tried smoking, even one or two puffs?" Those who indicated cigarette use were asked to identify the number of days of cigarette use in the last 30 days. Responses were recoded to indicate "Never," "Ever," and "Recent (past 30 days)" use. 


\section{E-cigarette use}

Participants were asked to identify whether they had ever used any electronic vapor products. Then, among those who indicated e-cigarette use, youths were asked to identify the number of days within the past 30 days they used e-cigarette products. Responses were recoded to indicate "Never," "Ever," and "Recent (past 30 days)" use.

\section{Cigar use}

Participants were asked on how many days in the past 30 days they had smoked cigars, cigarillos, or little cigars. Responses were dichotomized to indicate "No," or "Yes" use.

\section{Dip/chewing tobacco use}

Participants indicated how many days they used chewing tobacco, snuff, dip, snus, or dissolvable tobacco products in the past 30 days. Responses were dichotomized to indicate "No," or "Yes" to indicate use in the past 30 days.

\section{Covariates for latent class membership}

Variables used to examine correlates of membership in latent classes included sex, grade (9th through 12th) and marijuana use. Sex was determined by asking respondents "What is your sex?" Response options were limited to "Male" or "Female." Students indicated what grade in school they were in. Students were asked two questions related to marijuana use, which were combined and recoded to indicate "Never," "Ever," or "Recent" marijuana use.

\section{Statistical analysis}

LCA was utilized to explore and identify tobacco use profiles among Black adolescents using cigarette smoking, e-cigarette use, other combustible tobacco products, and other non-combustible tobacco products as latent class indicators. A series of latent class models specifying one to five classes was tested. Optimal model selection was based upon recommended indices including low Adjusted Bayesian Information Criterion (aBIC) relative to other models, significant Lo-Mendell-Rubin Likelihood Ratio Test (LMR/LRT), and acceptable quality of classification [31]. aBIC is based on the loglikelihood of each model with the lowest value providing support to select a particular model. The LMR/LRT tests for improvement of fit for the model under consideration compared with a model with one less class. A $p$-value greater than 0.05 indicate that the model with one less class fits best. All analyses were conducted using Mplus Version 8.1 [32]. The Mplus tools stratification, cluster, and weight were used to calculate the correct standard errors for the complex survey design of the YRBS; data were weighted to represent the U.S. population. Missing data for latent class indicators were accounted for using the full information maximum likelihood (FIML) capabilities of Mplus. After determining the appropriate number of classes, multinomial logistic regression was used to assess the role of sex, grade level, and marijuana use in association with tobacco use class membership [33]. Covariates were treated as auxiliary variables using the R3STEP function in Mplus, which initiates the multinomial regression and maintains the class structure while controlling for uncertainty in class assignment [33]. Post hoc cross tabulations to explore tobacco product use within class were conducted in SAS 9.4 and represent unweighted data.

Table 1 Grade Level, Sex, Substance Use Among Black 9th-12th Graders, 2017 National Youth Risk Behavior Survey $(n=2790)$

\begin{tabular}{ll}
\hline Characteristic & $\begin{array}{l}\boldsymbol{n} \\
\text { (weighted \%) }\end{array}$ \\
\hline Grade Level & \\
9th & $719(29.4)$ \\
10th & $717(26.1)$ \\
11th & $650(22.5)$ \\
12th & $703(22.0)$ \\
Sex & \\
Male & $1348(49.8)$ \\
Female & $1442(50.2)$ \\
Cigarette Use & \\
Never & $1558(79.8)$ \\
Ever & $326(15.2)$ \\
Recent use & $106(5.0)$ \\
E-Cigarette Use & \\
Never & $1773(70.6)$ \\
Ever & $507(20.8)$ \\
Recent use & $179(8.6)$ \\
Non-combustible tobacco product \\
use (i.e., chewing tobacco, snuff, \\
dip, or dissolvable tobacco) past \\
30 days
\end{tabular}




\section{Results}

As shown in Table 1, the sample was balanced by sex. Twenty-nine percent of the students were in the 9th grade, $26 \%$ were in the 10 th grade, $22 \%$ each were in 11 th and 12th grades. Most students reported no lifetime use of cigarettes (79.8\%) or e-cigarettes (70.6\%). Fifteen percent reported lifetime but not current cigarette smoking, whereas 5\% reported current cigarette use. One-fifth reported lifetime but not current ecigarette use, and $8.6 \%$ reported current e-cigarette use. Most also indicated no past 30-day use of other combustible tobacco products such as cigars and cigarillos (92.6\%), and no past 30-day use of non-combustible tobacco products including chewing tobacco, snuff, dip, or dissolvable tobacco (96.5\%). The prevalence of current marijuana use, $26.1 \%$, was higher than the prevalence for any of the tobacco use variables.

\section{Latent class analysis}

The comparison of model fit indicated that a three-class solution was optimal. As shown in Table 2, the latent class distribution highlighted three distinct profiles of tobacco use behaviors among Black high school students: Class 1 (Non-Users), Class 2 (E-Cigarette Users), and Class 3 (Polytobacco Users). Non-Users comprised the largest proportion of the sample $(80.9 \%)$, followed by Ecigarette users $(14.3 \%)$; $4.8 \%$ were classified as Polytobacco Users. Non-users were not engaged in tobacco use. E-cigarette users had low conditional probabilities for current use of cigars and cigarillos (0.169) and chewing tobacco, snuff, dip, or dissolvable tobacco (0.039); they had higher conditional probabilities for lifetime/ non-current use of cigarettes (0.480) and e-cigarettes (0.703) than the other two classes. Polytobacco users had the highest conditional probabilities for current use of cigarettes (0.738), e-cigarettes (0.771), cigars and cigarillos (0.813), and chewing tobacco, snuff, dip, or dissolvable tobacco (0.548).

Table 3 presents results from the multinomial logistic regression to explore sex, grade level, and marijuana use in association with classification relative to Non-Users. Relative to females, males had four times greater odds of being classified as Polytobacco Users class versus the non-user class $(\mathrm{aOR}=4.28,95 \% \mathrm{CI}$ : $1.62-11.35)$. Regarding grade level, ninth graders were less likely than twelfth graders to be classified as Polytobacco Users versus Non-users $(\mathrm{aOR}=0.32, \mathrm{CI}: 0.12-0.88)$. Students reporting current marijuana use (relative to never use) were statistically more likely to be classified as E-cigarette Users $(\mathrm{aOR}=26.13, \mathrm{CI}:$ 8.84-77.24) and Polytobacco Users $(\mathrm{aOR}=24.61, \mathrm{CI}$ : 6.95-87.11) than Non-users. Students reporting ever using marijuana use (relative to never using) had greater odds of being classified as E-cigarette Users than Non-Users (aOR = 12.45, CI: 4.05-38.29).

\section{Tobacco use behaviors among students in the Polytobacco user class}

Table 4 shows the prevalence of each tobacco use behavior among Polytobacco Users. Estimates of the prevalence of current use were highest for cigars and cigarillos (89.2\%) and cigarettes (84.5\%), followed by ecigarettes (69.6\%), and chewing tobacco, snuff, dip, or dissolvable tobacco products (55.7\%). Although $9.3 \%$

Table 2 Latent Classes of Tobacco Use Among Black 9th-12th Graders, 2017 National Youth Risk Behavior Survey $(n=2782)$

\begin{tabular}{|c|c|c|c|}
\hline Latent Class Indicators & $\begin{array}{l}\text { Class 1: } \\
\text { Non-Users } \\
\text { n (\%) } \\
2250(80.9)\end{array}$ & $\begin{array}{l}\text { Class 2: } \\
\text { E-Cigarette Users } \\
\text { n (\%) } \\
399(14.3)\end{array}$ & $\begin{array}{l}\text { Class 3: } \\
\text { Polytobacco Users } \\
\text { n (\%) } \\
133(4.8)\end{array}$ \\
\hline \multicolumn{4}{|l|}{ Cigarette use } \\
\hline Never & 0.907 & 0.467 & 0.149 \\
\hline Ever & 0.087 & 0.480 & 0.113 \\
\hline Recent use & 0.006 & 0.053 & 0.738 \\
\hline \multicolumn{4}{|l|}{ E-cigarette use } \\
\hline Never & 0.884 & 0.005 & 0.209 \\
\hline Ever & 0.115 & 0.703 & 0.020 \\
\hline Recent (30 day) use & 0.000 & 0.292 & 0.771 \\
\hline \multicolumn{4}{|l|}{ Cigar Use (past 30 days) } \\
\hline No & 0.997 & 0.831 & 0.187 \\
\hline Yes & 0.003 & 0.169 & 0.813 \\
\hline \multicolumn{4}{|c|}{ Dip/chewing tobacco Use (past 30 days) } \\
\hline No & 1.000 & 0.961 & 0.452 \\
\hline Yes & 0.000 & 0.039 & 0.548 \\
\hline
\end{tabular}


Table 3 Multinomial Regression of covariates associated with class membership relative to Class 1:Non-users, adjusted for sex, grade level, and marijuana use Among Black 9th-12th Graders, 2017 National Youth Risk Behavior Survey $(n=2595)$

\begin{tabular}{|c|c|c|}
\hline Covariates & $\begin{array}{l}\text { E-Cigarette Users } \\
\text { vs. Non-Users }\end{array}$ & $\begin{array}{l}\text { Polytobacco Users } \\
\text { vs. Non-Users }\end{array}$ \\
\hline Male Sex & $0.87(0.53-1.40)$ & $4.28(1.62-11.35)$ \\
\hline \multicolumn{3}{|l|}{ Grade Level } \\
\hline 9th & $0.78(0.38-1.59)$ & $0.32(0.12-0.88)$ \\
\hline 10th & $0.75(0.39-1.43)$ & $0.62(0.29-1.29)$ \\
\hline 11th & $1.31(0.56-3.04)$ & $0.41(0.17-1.01)$ \\
\hline 12th (REF) & - & - \\
\hline \multicolumn{3}{|l|}{ Marijuana Use } \\
\hline Recent (past 30 days) & $26.13(8.84-77.24)$ & $24.61(6.95-87.11)$ \\
\hline Ever & $12.45(4.05-38.29)$ & $1.59(0.09-27.84)$ \\
\hline Never (REF) & - & - \\
\hline
\end{tabular}

reported ever using cigarettes, and no students reported ever/lifetime use of e-cigarettes. Three-quarters of the students in the polytobacco class reported engaging in 2 or 3 of the four tobacco use behaviors (40.4 and $34.6 \%$, respectively).

Of the 133 students classified as Polytobacco Users, 67 reported seven unique combinations of tobacco use behaviors (Table 5). Specifically, more than one-fourth reported current use of all four behaviors (28.4\%), 22.4\% reported ever using other non-combustible tobacco products (chewing tobacco, snuff, dip, or dissolvable tobacco) and current use of the other three tobacco use

Table 4 Prevalence of tobacco use behaviors among Black adolescent Polytobacco Users $(n=133)$

\begin{tabular}{ll}
\hline Cigarette Use & \\
Never & $6.2 \%$ \\
Ever & $9.3 \%$ \\
Recent (past 30 days) use & $84.5 \%$ \\
E-Cigarette Use & \\
Never & $30.4 \%$ \\
Ever & $0.0 \%$ \\
Recent (past 30 day) use & $69.6 \%$ \\
Dip, chewing tobacco, snuff & \\
No & $44.3 \%$ \\
Yes & $55.7 \%$ \\
Cigars, cigarillos & \\
No & $10.8 \%$ \\
Yes & $89.2 \%$ \\
Number of Tobacco Use Behaviors & \\
One & $11.0 \%$ \\
Two & $40.4 \%$ \\
Three & $34.6 \%$ \\
Four & $14.0 \%$ \\
\hline
\end{tabular}

behaviors (i.e., cigarettes, other combustible tobacco products (cigars and cigarillos), and e-cigarettes). Additionally, $17.8 \%$ reported use of combustible tobacco products (i.e., cigarettes and other combustible tobacco products), but not use of e-cigarettes or non-combustible tobacco products.

\section{Discussion}

This study characterized patterns of polytobacco use among U.S. Black high school students. Our findings indicate that the prevalence of past 30-day use of each of the four tobacco use behaviors was $<10 \%$. Approximately $80 \%$ of the students were best classified as Non-Users, meaning they were largely not engaged in any of the tobacco use behaviors. This is consistent with studies demonstrating large declines in tobacco use among youth [12]; however, $14 \%$ were characterized as E-cigarette Users" and approximately $5 \%$ were characterized as Polytobacco Users. The importance of this investigation is highlighted by the persistence of tobacco-related health disparities experienced by Blacks, targeted marketing of the most harmful products to Black people by the tobacco industry, and comparatively limited access to tobacco use cessation programs among Black Americans [34-36].

We found only one recent study that examined polytobacco use among Black youth [23]. The results of that study identified two classes, which were deemed "NonUsers" and "Cigarette/cigar" groups. Males were more likely to be classified in "Cigarette/cigar" group and this class had higher odds of increased nicotine dependence. Those results are similar to the findings of the current study (males reporting higher odds of multiple tobacco product use); however, a key difference is the focus on current use only and smaller sample size $(n=852)$ [23]. The current study included lifetime use, which gives us an insight into what tobacco products Black youth might be more likely to experiment with. These data could be 
Table 5 Most prevalent unique combinations of tobacco use behaviors among Polytobacco users $(n=67)$

\begin{tabular}{llll}
\hline E-Cigarettes & Cigarettes & Dip, chewing tobacco, snuff & Cigars, Cigarillos \\
\hline Any past 30-day use & Any past 30-day use & Any past 30-day use & Any past 30-day use \\
Any past 30-day use & Any past 30-day use & No past 30-day use & Any past 30-day use \\
No lifetime use & Any past 30-day use & No past 30-day use & Any past 30-day use \\
Any past 30-day use & Any past 30-day use & No past 30-day use & No past 30-day use \\
No lifetime use & Lifetime use, no past 30-day use & No past 30-day use & Any past 30-day use \\
Any past 30-day use & Lifetime use, no past 30-day use & Any past 30-day use & Any past 30-day use \\
No lifetime use & Any past 30-day use & Any past 30-day use & Any past 30-day use \\
\hline
\end{tabular}

used to design preventive interventions before youth become current or frequent tobacco product users.

Youth in the E-cigarette Users class had a 70\% chance of lifetime use of e-cigarettes and nearly $50 \%$ chance of ever/lifetime smoking a cigarette. The $30 \%$ chance that youth in this class were currently using e-cigarettes is concerning. Assessments of the harm potential of ecigarettes are very limited. The e-liquids available for these products have a wide variation in nicotine content, and the amount of nicotine in many vials could be fatal if ingested orally or transdermally [21]. The variation in the amount of nicotine and other potentially harmful ingredients contained in tobacco products as well as differences in how products are used (e.g., how often and quantity consumed) [37] increase the importance of understanding which products are being used by youth. Little is known about the true harm reduction value or addiction reduction potential of alternate products (e.g., hookah or e-cigarettes) relative to combustible cigarettes. For example, there is research that suggests one hookah session could be the equivalent of toxicant exposure of smoking 1 to 50 cigarettes [38]. Further, Freiberg et al. (2009) found that hookah produced a significantly higher carbon monoxide exposure while delivering the same amount of nicotine in a laboratorycontrolled experiment compared to cigarettes [39].

Polytobacco Users had a high likelihood of current use of all four forms of tobacco/nicotine use included in the present study. Specifically, Polytobacco Users had a 54\% chance of past 30-day smokeless tobacco use, $81 \%$ chance of current cigar use, and $77 \%$ chance of past 30 day electronic cigarette use. Further analysis indicates that $75 \%$ of these youth had used two or three tobacco products concurrently in the last 30 days, with cigars and cigarettes having the highest use prevalence. Our findings raise the possibility that a sizeable subgroup of Black teens may benefit from interventions targeting multiple product use, and e-cigarette and cigar use specifically. Concurrent use of tobacco products places Black polytobacco users at increases risk of poor health consequences among Black Polytobacco Users. The literature has long supported that U.S.
Blacks smoke fewer cigarettes per day [1, 40], take fewer puffs per cigarette [41]-all while experiencing higher rates of tobacco-related deaths from coronary heart disease, stroke and lung cancer $[1,11]$.

Relative to the non-user class, males (vs. females) were more likely to be Polytobacco Users and 9th graders (vs. 12th graders) were less likely be in the Polytobacco Users class. Black males and older youth are at greater risk of being Polytobacco Users and could benefit from targeted programming. Further, current marijuana use (vs. never use) was associated with an over 20-fold increased odds of being classified as E-cigarette Users or Polytobacco Users compared to Non-Users. The present study confirms prior findings of the significant association of marijuana use with tobacco use [15, 17] and highlights the need for prevention scientists to consider comorbid intervention designs.

The present study has limitations. Data were selfreported from youth and as such substance use behaviors could have been over- or under-reported. The YRBSS survey is not all inclusive of all tobacco products (e.g., hookahs) and the data are cross-sectional, so causality cannot be determined. Notwithstanding, these findings represent a nationally representative sample of Black youth and fill an important gap in the pertinent literature.

\section{Conclusions}

This research suggests the need to examine the unique effects of polytobacco use on Black Americans, given the excess morbidity and mortality associated with use. Tobacco use in any form is unsafe [42]; therefore, there has been increased public health concerns about use of multiple tobacco products, also referred to as polytobacco use, among U.S. adolescents [26, 27]. The harmful effects of tobacco use may be heightened when marijuana is also used [43, 44]. For example, respiratory problems were found to be more common among those who concurrently used tobacco and marijuana [17]. Future research should incorporate longitudinal assessments of the health and social consequences of polytobacco use with marijuana. 


\section{Acknowledgements}

None.

\section{Authors' contributions}

TG conceptualized and designed study, as well as analyzed and interpreted the data. TG, DD, and FAM drafted the article. FAM and AH assisted with conceptualization, data interpretation, editing/revising the article and formatting citations. RJ provided critical feedback and revision to the entire manuscript. All authors read and approved the final manuscript.

\section{Funding}

None.

\section{Availability of data and materials}

Youth Risk Behavior Surveillance System (YBRSS) data are publicly available through the Centers for Disease Control and Prevention website: https:// www.cdc.gov/healthyyouth/data/yrbs/index.htm

\section{Ethics approval and consent to participate}

This study was exempt from ethics approval due to its use of secondary deidentified publically available data pursuant to United States Code of Federal Regulations $\$ 46.101$ and $\$ 46.104$

\section{Consent for publication}

Not applicable.

\section{Competing interests}

The authors declare that they have no competing interests.

\section{Author details}

'Department of Health \& Kinesiology, College Station, Texas A \& M University, 267 Gilchrist, 4243 TAMU, College station, TX 77843-4243, USA. ${ }^{2}$ Johns Hopkins School of Nursing, Baltimore, MD, USA. ${ }^{3}$ Division of Intramural Research, National Institute for Minority Health Disparities, Bethesda, MD 20892, USA. ${ }^{4}$ Division of Adolescent and Young Adult Medicine, UPMC Children's Hospital of Pittsburgh, Department of Pediatrics, University of Pittsburgh School of Medicine, Pittsburgh, PA, USA.

${ }^{5}$ Department of Mental Health, Johns Hopkins Bloomberg School of Public Health, Baltimore, MD, USA.

Received: 16 July 2020 Accepted: 12 January 2021

Published online: 23 January 2021

\section{References}

1. USDHHS. Tobacco Use Among U.S. Racial/Ethnic Minority Groups- African Americans, American Indians and Alaska Natives, Asian Americans and Pacific Islanders, and Hispanics. Atlanta: U.S Department of Health and Human Services; 1998.

2. American Cancer Society. Cancer facts \& figures for African Americans 2016-2018. Atlanta: American Cancer Society; 2016.

3. Simmons VN, Piñeiro B, Hooper MW, Gray JE, Brandon TH. Tobacco-related health disparities across the cancer care continuum. Cancer Control. 2016; 23(4):434-41.

4. USDHHS. Tobacco's Health Impact on Adolescents 2016 [Available from: https://www.hhs.gov/ash/oah/adolescent-development/substance-use/ drugs/tobacco/health-impact/index.html. Accessed 22 Apr 2019.

5. Mokdad AH, Marks JS, Stroup DF, Gerberding JL. Actual causes of death in the United States, 2000. Jama. 2004;291(10):1238-45.

6. National Center for Health Statistics Health, United States, 2007 With Chartbook on Trends in the Health of Americans Hyattsville, MD: 2007 Library of Congress Catalog Number 76-641496. For sale by Superintendent of Documents U.S. Government Printing Office.

7. Moolchan ET, Franken FH, Jaszyna-Gasior M. Adolescent nicotine metabolism: ethnoracial differences among dependent smokers. Ethnicity Dis. 2006;16(1):239-43.

8. Moolchan ET, Parzynski CS, Jaszyna-Gasior M, Collins CC, Leff MK, Zimmerman DL. A link between adolescent nicotine metabolism and smoking topography. Cancer Epidemiol Biomark Prev. 2009;18(5):1578-83.

9. Schoedel KA, Hoffmann EB, Rao Y, Sellers EM, Tyndale RF. Ethnic variation in CYP2A6 and association of genetically slow nicotine metabolism and smoking in adult Caucasians. Pharmacogenetics. 2004;14(9):615-26.
10. Gardiner PS. The African Americanization of menthol cigarette use in the United States. Nicotine Tob Res. 2004:6(Suppl 1):S55-65.

11. USDHHS. The health consequences of smoking -50 years of progress: $a$ report of the Surgeon General. Atlanta, GA: US Department of Health and Human Services, Centers for Disease Control and Prevention, National Center for Chronic Disease Prevention and Health Promotion, Office on Smoking and Health; 2014. p. 17.

12. Wang TW, Gentzke A, Sharapova S, Cullen KA, Ambrose BK, Jamal A. Tobacco product use among middle and high school students - United States, 2011-2017. MMWR Morb Mortal Wkly Rep. 2018;67(22):629-33.

13. Wang TW, Gentzke AS, Creamer MR, Cullen KA, Holder-Hayes E, Sawdey MD, et al. Tobacco product use and associated factors among middle and high school students - United States, 2019. MMWR Surveill Summ. 2019;68(12):1-22.

14. U.S. Department of Health and Human Services. E-cigarette Use Among Youth and Young Adults: A Report of the Surgeon General. Atlanta, GA: U.S Department of Health and Human Services, Centers for Disease Control and Prevention, National Center for Chronic Disease Prevention and Health Promotion, Office on Smoking and Health; 2016.

15. Ramo DE, Liu H, Prochaska JJ. Tobacco and marijuana use among adolescents and young adults: a systematic review of their co-use. Clin Psychol Rev. 2012;32(2):105-21.

16. USDHHS. Preventing Tobacco Use Among Youth and Young Adults: A Report of the Surgeon General Atlanta, GA: National Center for Chronic Disease Prevention and Health Promotion, Office on Smoking and Health; 2012 [Available from: https://www.surgeongeneral.gov/library/reports/ preventing-youth-tobacco-use/full-report.pdf. Accessed 22 Apr 2019.

17. Strong DR, Myers MG, Pulvers K, Noble M, Brikmanis K, Doran N. Marijuana use among US tobacco users: findings from wave 1 of the population assessment of tobacco health (PATH) study. Drug Alcohol Depend. 2018;186:16-22.

18. Centers for Disease Control and Prevention. Tobacco Use among middle and high school students-United States, 2011-2014. Morbidity Mortality Weekly Rep (MMWR). 2015;64(14):381-5.

19. Nguyen $H$, Reuter $P$. How risky is marijuana possession? Considering the role of age, race, and gender. Crime Delinq. 2012;58(6):879-910.

20. Harrell PT, Naqvi SMH, Plunk AD, Ji M, Martins SS. Patterns of youth tobacco and polytobacco usage: the shift to alternative tobacco products. Am J Drug Alcohol Abuse. 2017;43(6):694-702.

21. Gilreath TD, Leventhal A, Barrington-Trimis JL, Unger JB, Cruz TB, Berhane K, et al. Patterns of alternative tobacco product use: emergence of hookah and e-cigarettes as preferred products amongst youth. J Adolesc Health. 2016;58(2):181-5.

22. Sutter ME, Everhart RS, Miadich S, Rudy AK, Nasim A, Cobb CO. Patterns and Profiles of Adolescent Tobacco Users: Results From the Virginia Youth Survey. Nicotine Tobacco Res. 2018:20(suppl_1):S39-47.

23. Choi HJ, Yu M, Sacco P. Racial and ethnic differences in patterns of adolescent tobacco users: a latent class analysis. Child Youth Serv Rev. 2018; 84:86-93.

24. Gilreath TD, Connell CM, Leventhal AM. Tobacco use and suicidality: latent patterns of co-occurrence among black adolescents. Nicotine Tob Res. 2012; 14(8):970-6.

25. Juon H-S, Ensminger ME, Sydnor KD. A longitudinal study of developmental trajectories to young adult cigarette smoking. Drug Alcohol Depend. 2002; 66(3):303-14.

26. Lee YO, Pepper JK, MacMonegle AJ, Nonnemaker JM, Duke JC, Porter L. Examining youth dual and Polytobacco use with E-cigarettes. Int J Environ Res Public Health. 2018;15(4):699.

27. Osibogun O, Taleb ZB, Bahelah R, Salloum RG, Maziak W. Correlates of polytobacco use among youth and young adults: findings from the population assessment of tobacco and health study, 2013-2014. Drug Alcohol Depend. 2018;187:160-4

28. Dai H. Single, dual, and poly use of flavored tobacco products among youths. Prev Chronic Dis. 2018;15:E87.

29. Collins L, Lanza S. Latent Class and Latent Transition Analysis: With Applications in the Social, Behavioral, and Health Sciences; 2010.

30. Brener ND, Kann L, Shanklin S, Kinchen S, Eaton DK, Hawkins J, et al. Methodology of the youth risk behavior surveillance system-2013. Morbidity Mortality Weekly Rep Recomm Rep. 2013;62(1):1-20.

31. Nylund $\mathrm{KL}$, Asparouhov T, Muthén BO. Deciding on the number of classes in latent class analysis and growth mixture modeling: a Monte Carlo simulation study. Struct Equ Model. 2007;14(4):535-69. 
32. Muthén LK, Muthén BO. Mplus User's Guide. Eighth ed. Los Angeles, CA Muthén \& Muthén; 1998-2017.

33. Asparouhov T, Muthén B. Auxiliary variables in mixture modeling: three-step approaches using M plus. Struct Equ Model Multidiscip J. 2014;21(3):329-41.

34. Grier SA, Kumanyika SJA. Targeted marketing and public health. Annu Rev Public Health. 2010;31:349-69.

35. Ribisl KM, D'Angelo H, Feld AL, Schleicher NC, Golden SD, Luke DA, et al. Disparities in tobacco marketing and product availability at the point of sale: results of a national study. Prev Med. 2017;105:381-8.

36. Webb Hooper M, Antoni MH, Okuyemi K, Dietz NA, Resnicow K. Randomized controlled trial of group-based culturally specific cognitive behavioral therapy among African American smokers. Nicotine Tob Res. 2017;19(3):333-41. https://doi.org/10.1093/ntr/ntw181.

37. Fagerström K, Eissenberg T. Dependence on tobacco and nicotine products: a case for product-specific assessment. Nicotine Tob Res. 2012;14(11):138290. https://doi.org/10.1093/ntr/nts007.

38. Cobb C, Ward KD, Maziak W, Shihadeh AL, Eissenberg T. Waterpipe tobacco smoking: an emerging health crisis in the United States. Am J Health Behav. 2010:34(3):275-85.

39. Freiberg MJA. Federal Approaches to the Regulation of Noncigarette Tobacco Products. Am J Prev Med. 2012;43(5 Suppl 3):S249-54. https://doi. org/10.1016/j.amepre.2012.07.036.

40. Clark PI, Gautam S, Gerson LW. Effect of menthol cigarettes on biochemical markers of smoke exposure among black and white smokers. Chest. 1996; 110(5):1194-8.

41. McCarthy WJ, Caskey NH, Jarvik ME, Gross TM, Rosenblatt MR, Carpenter C. Menthol vs nonmenthol cigarettes: effects on smoking behavior. Am J Public Health. 1995;85(1):67-72.

42. Jamal A, Gentzke A, Hu SS, Cullen KA, Apelberg BJ, Homa DM, et al. Tobacco use among middle and high school students—United States, 2011-2016. MMWR Morb Mortal Wkly Rep. 2017;66(23):597.

43. Lanza ST, Vasilenko SA, Dziak JJ, Butera NM. Trends among US high school seniors in recent marijuana use and associations with other substances: 1976-2013. J Adolesc Health. 2015;57(2):198-204.

44. Unger JB, Soto DW, Leventhal A. E-cigarette use and subsequent cigarette and marijuana use among Hispanic young adults. Drug Alcohol Depend. 2016;163:261-4.

\section{Publisher's Note}

Springer Nature remains neutral with regard to jurisdictional claims in published maps and institutional affiliations.

Ready to submit your research? Choose BMC and benefit from:

- fast, convenient online submission

- thorough peer review by experienced researchers in your field

- rapid publication on acceptance

- support for research data, including large and complex data types

- gold Open Access which fosters wider collaboration and increased citations

- maximum visibility for your research: over $100 \mathrm{M}$ website views per year

At $\mathrm{BMC}$, research is always in progress.

Learn more biomedcentral.com/submissions 